Session TD4-1

\title{
BUILDING INFORMATION MODELING AND SUSTAINABILITY
}

\author{
Pandya Paragkumar U \\ Civil Engineering Graduate Student \\ Lamar University \\ Dr.Enno “Ed” Koehn, P.E., F.ASCE \\ Professor, Civil Engineering Department \\ Lamar University
}

\begin{abstract}
Building Information Modeling (BIM) is a building design methodology characterized by the creation and use of coordinated and internally consistent computable information about a building project in design and construction. BIM is an association of digital information with each component placed in the building model. This information can be leveraged by downstream user's further improving productivity and quality of the process.

And what is Sustainable design or Green Building? It is sustainable site planning, improving indoor environmental quality, safeguarding water and water efficiency, energy efficiency and renewable energy, in addition to conservation of materials and resources ${ }^{1}$.

The paper investigates how these two different items could be developed on one platform to give the best result for Building Performance Analysis or Developing Sustainable Design for Green Buildings. An approach utilizing the concept of Leadership in Energy and Environmental Design (LEED) is recommended.
\end{abstract}

\section{Introduction}

No direct result of a specific problem was presented in this paper. It is, however, a study of present developments in the relation between BIM and sustainability. In particular, the methodology utilized presents information and definition from company websites since few books in this area have been published. In addition, there are a minimum number of research papers regarding the combination of BIM and sustainability.

\section{BIM and Sustainability}

The Building Information Modeling (BIM) according to National Institute of Building Sciences Facilities Information Council Published a Model Standard (NBIM) in which it defines BIM as “collaborative process” rather than simply a computer model ${ }^{2}$. 
BIM makes a reliable digital representation of the building available for design decision making, high-quality construction document production, construction planning and performance predication and cost estimates. It has the ability to keep information up-to date and accessible in an integrated digital environment.

BIM covers geometry, spatial relationships, geographic information, quantities and properties of building components (for example manufacturers' details). It can be used to demonstrate the entire building life cycle including the processes of construction and facility operation. Quantities and shared properties of materials can easily be extracted. Scope of work can be isolated and defined. Systems, assemblies, and sequences are able to be shown in a relative scale with the entire facility or group of facilities.

BIM methodology can provide rich association of digital, information with each component placed in the building model. This digital information can then be leveraged by downstream users, further improving productivity and the quality of the process.

BIM is needed because it integrates the work, process and information of

- Multiple disciplines ( engineers, architects, specialists )

- Multiple companies ( partners, clients, contractors )

- Multiple Project Phases ( design, construction, operation )

BIM uses are as follows:

- Design Visualization

- Design assistance and constructability review

- Site planning and sequencing

- Cost estimating

- Integration of subcontractor and supplier data

- System coordination

- Layout and field work

- Prefabrication

- Operation and maintenance

The different softwares used for BIM are as follows ${ }^{3}$ :

ArchiCAD from Graphisoft

ARRIS ${ }^{\circledR}$ from Sigma Design in arriscad.com

ArtrA from AEC Design Group

AutoCAD Architecture from [Autodesk]

Bentley Architecture from Bentley Systems

BiscoPro from Building Integration Software Company

BuildersCAD ${ }^{\circledR}$ from Sigma Design in builderscad.com

Proceedings of the 2009 ASEE Gulf-southwest Annual Conference Baylor University

Copyright $\left({ }^{\circ}\right.$ 2009, American Society for Engineering Education 
Building Explorer BIM Analysis (Estimating, Scheduling, Bidding)

Constructor from Graphisoft

Data Design System

Digital Project from Gehry Technologies LLC.

DProfiler from Beck Technology

Envisioneer from Cadsoft Corporation

IFC Engine Series from TNO

Javelin software from iLevel

MagiCAD from Progman

MiTek eFrame from MiTek Holdings, Inc.

MiTek TrussFramer from MiTek Holdings, Inc.

NAVIScheck File Manager from NAVIScheck.com

NavisWorks JetStream from Autodesk

ONUMA Planning System (OPS) from ONUMA, Inc.

RoomData ${ }^{\circledR}$ from Project Blueprint

SmartBIM ${ }^{\circledR}$ from Reed Construction Data

SoftPlan from SoftPlan Systems Inc.

Solibri Model Checker from Solibri

SPIRIT from SOFTTECH GmbH

StruCad from AceCad Software Inc.

Revit from Autodesk

Tekla Structures from Tekla Corporation

Virtual Environment from Integrated Environmental Solutions

VectorWorks Architect from Nemetschek N.A. (a subsidiary of Nemetschek AG)

The benefits of BIM are summarizes as follows ${ }^{4}$ :

1. Integration

2. Single model for both structural analysis and documentation

3. Bidirectional associativity between model and views

4. Construction documents

5. Structural details

6. DWG/DXF/DGN/IFC AND CIS/2 Support

7. Multi-user work sharing

8. Interoperability 


\section{Integration:-}

- Integration saves time, and increases the productivity and creates less error which in direct context saves money and increases the profitability of a company.

- DESIGN: Increases opportunity for design iterations and allows for a quick Exchange of information between disciplines.

- Documentation : Spend less time on grunt work

Spend less time for documenting, avoid redundant efforts.

- Construction : Fast tracking of work, Managed schedules, Design /Build

Single Model for both Structural Analysis and documentation:-BIM combines a physical model of the building fully associated with an editable analytical model and may be used by third party structural analysis applications. Any design changes made during analysis automatically updates the physical model as well as the construction documents.

Bidirectional associativity between models and views: - In the BIM software every 2D and 3D view, every drawing sheet, every detail and every schedule is a direct presentation of information from the same underlying building database. Anytime you make changes the software propagates those changes throughout the model and updates every related plan, section, elevation or schedule.

Construction documents:-The BIM automates the repetitive manual drafting tasks required in conventional CAD systems. Cut sections, elevations and call out details reference sections and details are automatically reviewed in accordance to sheet numbers. Bidirectional associativity means that any change in any view is propagated in every related view so drawings stay fully coordinated.

Structural Details:-The BIM software creates details from views of a 3D model with additional annotations, or from scratch with BIM software 2D drafting tools, or imports them from conventional computer aided design (CAD) files. In order to save time, entire sheets of typical details in DWG format from previous projects may be imported. Dedicated drafting tools are available, specially for steel and reinforced concrete details such as welding symbols, anchor bolts, rebars, concrete area reinforcements and more.

DWG/DXF/DGN/IFC/ AND CIS/2 SUPPORT:- Most of the BIM software imports, exports and links your data with industry leading formats, including DWG ${ }^{\mathrm{TM}}$, DXFTM, DGN, IFC and CIS/2.So you can work with various consultant, client or contractor data. The BIM software supports the traditional workflow where structural modeling starts with DWG files provided by the architect using CAD software. Also BIM software exports 3D models to CAD where structural properties can be queried.

Bidirectional links with multiple analyses: - The BIM software having analytical models is bidirectional linked with external structural analysis and design programs. Bidirectional linking means that analysis results accurately and automatically update your model if any member size has changed. A parametric change technology coordinates those updates everywhere in your project views and construction drawings. Examples of structural analytical information that can 
be shared with structural analysis and design programs include release and boundary conditions, loads and load combinations and material and section properties.

Multi-user work sharing: - Multiple users can share the same intelligent building information model and save their work to one central file. Work sharing provides a complete range of collaboration modes within a structural engineering firm, between engineers and drafters, and within an architectural engineering firm, between engineers, architects and drafters.

Interoperability:-Structural Engineers, Mechanical, Electrical and Plumbing Engineers (MEP) as well as architects can take full advantage of the BIM platform and work more efficiently on the same shared database, and perform interference checking between architectural, structural and MEP elements. For ultimate coordination they can receive electronic notifications about the design changes made by other parties.

\section{SUSTAINABLE DESIGN}

But one thought comes to mind what Sustainable Design is? Sustainable Design is sustainable site planning, improving indoor environmental quality, safeguarding water and water efficiency, energy efficiency and renewable energy, in addition to conservation of materials and resources.

Why are we interested in implementing this concept in buildings? Because rapidly accelerating climate change caused by greenhouse gas (GHG) emissions, is now fueling dangerous regional and global environmental events. Data from the U.S. Energy Information Administration illustrates that buildings are responsible for almost half $(48 \%)$ of all GHG emissions annually. Seventy-six percent of all electricity generated by US power plants goes to supply the Building Sector as shown in Figure 1 below $^{5}$. Therefore, immediate action in the Building Sector is essential if we are to avoid hazardous climate change.

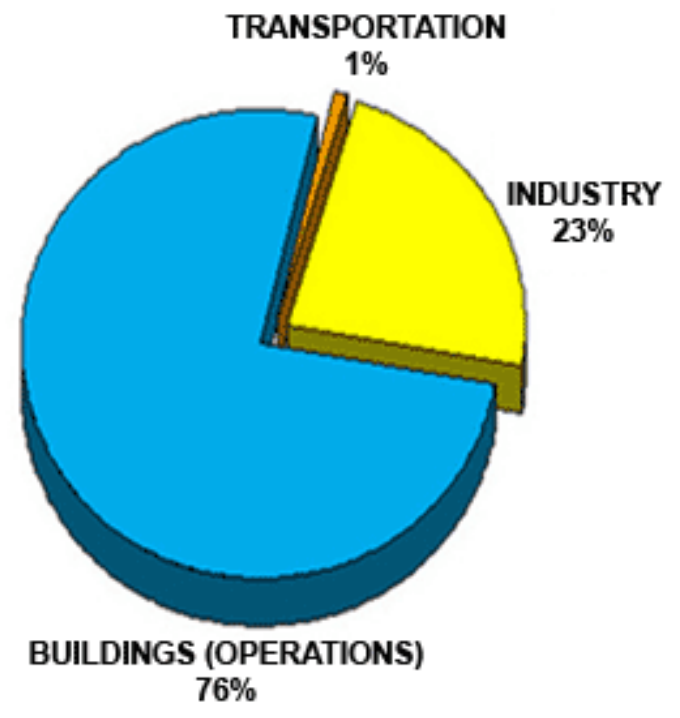

Fig 1 
BIM offers capabilities beyond performance modeling by simplifying take-offs, estimating, and offering a potential avenue for instant feedback on the ecological functions of a design. BIM is a methodology as much as it is software, centering on models embedded with information that designers can use for a variety of purposes.

Architectural design programs and building performance analysis programs have been widely used as separate tools since the 1980s, but recent developments are beginning to integrate design software with tools to simulate and predict daylighting, energy and water use, heating and cooling needs, and airflow in buildings. Early-stage energy modeling can increase building efficiency by providing architects with predicted performance data before a design is fully developed.

\section{How BIM and Building performance analysis work together?}

Energy modelers use specialized software to create a virtual model of a building. They then subject that model to the building's anticipated weather and usage patterns to predict its heating and cooling loads and energy use. Until now, setting up an energy model took many hours, even for a relatively simple building, so iterations through various design alternatives were slow and expensive. Now, since the model is available as a actual building, which was created in BIM software we can shorten time required for a building performance analysis.

One of the ironies of energy modeling and other simulations used in the design process is that they tend to require a fairly complete model of the building, which means that by the time the modeling is done, the design is fully developed and only minor changes can be entertained. BIM mitigates this problem to some extent because the integrated 3D design model makes it relatively easy to make changes, even late in the process, by eliminating the need to coordinate changes across multiple drawings. Early-stage simulations from preliminary 3D and BIM models offer the greatest potential ${ }^{6}$.

\section{Analysis during design development}

More detailed energy analyses during design development, or verifying a building's performance from the construction documents, is the traditional purview of mechanical engineers who specialize in energy modeling. Simply by translating building geometry automatically from a design model, 3D CAD and BIM tools have the potential to dramatically reduce the amount of time and effort required to develop these energy models. As noted above, that translation can be done from Revit and ArchiCAD. A more generic approach, developed by the Industry Alliance for Interoperability, uses a data structure termed Industry Foundation Classes (IFC) but, support of the IFC standard has been spotty and the IFC definitions don't cover all building data exchange requirements. Finally, there are several efforts at direct bilateral connections between BIM tools and performance modeling platforms. The following sections describe how the major BIM software tools support this type of analysis ${ }^{6}$. 


\section{Building performance analysis software}

Here is the some information regarding the building performance analysis software.As it is not possible to explain each and every software in full detail we have explained some of them in brief form.

1) Green Building Studio ${ }^{7}$ (GBS):- It is pioneer in the field of easy, basic energy simulation from design models. GBS includes a protocol for translating information from CAD software into the industry standard DOE-2 energy simulation engine. For example, a person using Revit can have an output file in gbXml format (an information exchange protocol developed by GBS) and software uploads to GBS's server for analysis. Minutes later the designer can download the results of the model.

2) Sketchup and Energyplus ${ }^{8}$ : - Google sketchup offers a 3D modeling interface and the ability to assign characteristics to objects in the design. As most of the mainstream design tools have at least some capability to import models from Sketchup and to export simple models out of it. The sketchup plug-in required for the powerful Energyplus modeling engine is also available. This plug-in which is available for both the free and the full versions of Sketchup will help users define HVAC zones and assign thermal characteristics to elements in the model, and it can also be exported to an Energyplus input file to run separately.

3) Revit MEP Links to IES $^{9}$ :-Revit MEP combined with the IES can calculate heating and cooling loads directly using an IES engine. IES's Virtual Environment is an integrated performance modeling package that models energy use, day lighting, computational fluid dynamics (CFD), and other attributes based on a single shared model of the building. Revit MEP in combination with a virtual environment toolkit can perform additional complex and sophisticated analyses of building models as shown in Figure 2.

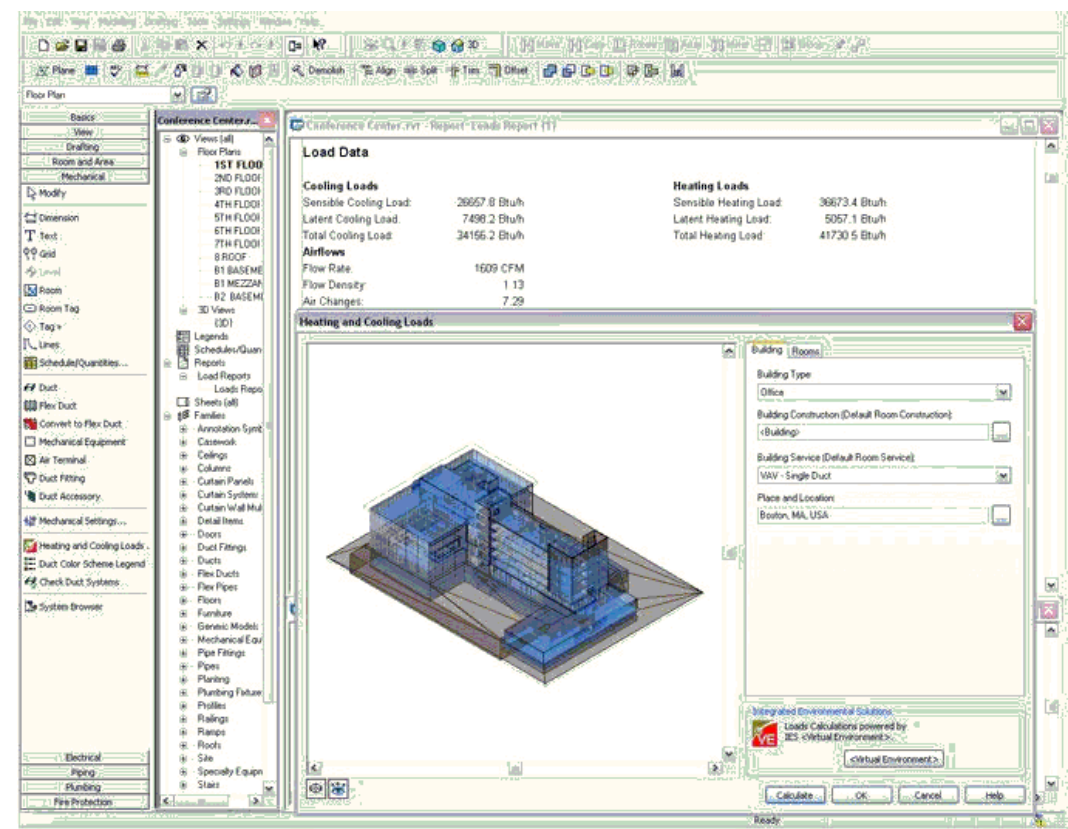

Fig 2:-Revit MEP shows the heating and cooling load calculator from IES Virtual Environment running within the Revit application.

Proceedings of the 2009 ASEE Gulf-southwest Annual Conference Baylor University

Copyright $($ C) 2009, American Society for Engineering Education 
4) Ecotect $^{10}$ :- This software is used for building design and environmental analysis. It also is a valuable player in this field because it has a connection to open-source tools such as Radiance for day lighting modeling and Energy Plus in which ecotect users can perform more robust simulations that are beyond the scope of its internal code .It can also perform Shadows \& Reflections, Solar Analysis, Lighting Design, Right-to-Light, Acoustic Analysis, Thermal Analysis, Ventilation \& Air Flow, Building Regulations, and Resource Management etc.

5)IES ${ }^{11}$ ( Integrated Environmental Solutions):- IES offers a comprehensive package of building performance analysis tools that enable designers to look at how key design and climate factors influence the sustainable performance of a building. It also performs CFD calculations, thermal calculations, lighting design etc and provides a plug-in to Google Sketchup and Autodesk Revit called Virtual Environment in which the building performance can be evaluated .How BIM and analysis tools interact is shown in Figure 3.

\begin{tabular}{|c|c|c|c|c|}
\hline & Autodesk Revit & Graphisoft ArchiCAD & Bentley Microstation & SketchUp \\
\hline \multicolumn{5}{|l|}{$\begin{array}{l}\text { Integrated modeling } \\
\text { tools }\end{array}$} \\
\hline $\begin{array}{l}\text { IES Virtual } \\
\text { Environment }\end{array}$ & $\begin{array}{l}\text { Revit MEP runs heating } \\
\text { and cooling load tool } \\
\text { directly; exports to IES } \\
\text { via gbXML and native } \\
\text { graphic file format for more } \\
\text { sophisticated analyses. }\end{array}$ & $\begin{array}{l}\text { ArchiCAD exports gbXML, } \\
\text { which can be run in IES } \\
\text { Virtual Environments. }\end{array}$ & $\begin{array}{l}\text { Models can be } \\
\text { transferred using } \\
\text { graphic exchange } \\
\text { format and traced, or } \\
\text { using IFCs. }\end{array}$ & \\
\hline Ecotect & $\begin{array}{l}\text { Revit exports gbXML, which } \\
\text { can be run in Ecotect. }\end{array}$ & $\begin{array}{l}\text { ArchiCAD gbXML exports } \\
\text { can run in Ecotect. Building } \\
\text { geometry can also be } \\
\text { converted using graphic } \\
\text { file formats. }\end{array}$ & $\begin{array}{l}\text { Models can be } \\
\text { tronsferred using } \\
\text { graphic exchange } \\
\text { format and traced. }\end{array}$ & \\
\hline \multicolumn{5}{|l|}{$\begin{array}{l}\text { Energy-only } \\
\text { modeling tools }\end{array}$} \\
\hline $\begin{array}{l}\text { Green Building Studio } \\
\text { (DOE-2) }\end{array}$ & $\begin{array}{l}\text { Revit's gbXML plug-in cleans } \\
\text { up and exports the model } \\
\text { to GBS. }\end{array}$ & $\begin{array}{l}\text { ArchiCAD's gbXML plug-in } \\
\text { cleans up and exports the } \\
\text { model to GBS. }\end{array}$ & Not supported. & \\
\hline EnergyPlus & Not supported directly. & $\begin{array}{l}\text { ArchiCAD utility makes } \\
\text { it easy to combine rooms } \\
\text { into HVAC zones for } \\
\text { export to EneravPlus. }\end{array}$ & $\begin{array}{l}\text { Models can be } \\
\text { transferred using IFCs. }\end{array}$ & $\begin{array}{l}\text { Direct plug-in } \\
\text { announced for } \\
\text { release in spring } \\
\text { of } 2007 \text {. }\end{array}$ \\
\hline
\end{tabular}

Figure 3 Interaction

\section{Conclusion}

The building and facility industry today demands more project visibility, lower costs, better risk management (scheduling and costs) and most importantly is sustainable development. Thus the use of BIM -- both the technology and changes in increased collaboration -- allows for significant exchange of information between all stakeholders over the lifecycle of the facility: 
owners, architects, engineers, contractors and operators. This information includes that associated with green technology: efficiencies in energy use, increased emphasis on environmental health and the drive to generate less waste. Not only can BIM optimize building performance, less waste generation during construction, and improved energy management during operation, it can accelerate certification for LEED status. Thus the amalgamation of BIM and Sustainability can assist in for securing a green future.

\section{References}

1. URL: http://www.bimsummits.com/newyork/bimsummit-sessions.html/.

2. URL: http://www.buildingsmartalliance.org/nbims/about.php/.

3. URL:http://en.wikipedia.org/wiki/Building_Information_Modeling /.

4. URL:http://usa.autodesk.com/company/building-information-modeling/.

5. URL: http://www.architecture2030.org/current_situation/building_sector.html/.

6. URL: http://www.buildinggreen.com/.

7. URL: http://usa.autodesk.com/adsk/servlet/index?id=11179508\&siteID=123112/.

8. URL: http:// www.sketchup.google.com/.

9. URL:http://resources.autodesk.com/adsk/servlet/Revit-MEP/overview.htm

10. URL: http://ecotect.com/products/ecotect/features/.

11. URL: http://www.iesve.com/content/.

\section{Bibliography}

1. URL:http://www.google.com/search?hl=en\&q=BIM\&btnG=Google+Search\&aq=f\&oq=/.

2. URL:http://www.bentley.com/.

3. URL: http://www.usgbc.org/.

4. URL: http://www.leedbuilding.org/.

5. URL: http://www.cenews.com/.

6. URL: http://www.graphisoft.com/.

7. URL: http://en.wikipedia.org/wiki/Industry_Foundation_Classes/.

8. URL: http://www.wbdg.org/pdfs/jbim_fall07.pdf/.

9. URL: http://www.gbxml.org/about.htm/.

10. URL: http://usa.autodesk.com/company/building-information-modeling/sustainability/.

\section{ENNO KOEHN, LAMAR UNIVERSITY}

Dr.Enno "Ed" Koehn is Professor of Civil Engineering at Lamar University. Dr.Koehn has served as the principle investigator for several research and development projects dealing with various aspects of construction. He also has experience in the design, scheduling, and estimating of facilities. He has authored/co-authored over 200 papers in engineering education, as well as the general areas of civil and construction engineering. Dr.Koehn is a member of ASEE, AACE International, ASCE, NSCE, Chi Epsilon, Tau Beta Pi, Sigma Xi, and is a registered Professional engineer and surveyor.

\section{PARAGKUMAR PANDYA, LAMAR UNIVERSITY}

Paragkumar Pandya is civil engineering graduate student. He has two years of engineering experience working for a consultant in structural analysis and design. Paragkumar Pandya is student member of ASCE.

Proceedings of the 2009 ASEE Gulf-southwest Annual Conference

Baylor University

Copyright ( () 2009, American Society for Engineering Education 
Proceedings of the 2009 ASEE Gulf-southwest Annual Conference Baylor University

Copyright $($ ) 2009, American Society for Engineering Education 